\title{
ANALISIS NILAI-NILAI KARAKTER DALAM PEMBELAJARAN EKSTRAKURIKULER DRUM BAND
}

\author{
Meiyani Lutfil Khoiriyah ${ }^{1}$, Aries Tika Damayani ${ }^{2}$, Rofian $^{3}$ \\ 1,2,3 Jurusan PGSD, UPGRIS, \\ e-mail: meiyani.vivi@gmail.com, damayaniariestika@gmail.com, kotakomik.pian@gmail.com
}

\begin{abstract}
ABSTRAK
Jenis penelitian ini adalah deskriptif kualitatif. Penelitian ini menggunakan metode pengumpulan data berupa observasi, wawancara, dan dokumentasi. Hasil analisis data bahwa pelaksanaan kegiatan ekstrakurikuler drum band dilaksanakan setiap hari Sabtu. Siswa yang mengikuti ekstrakurikuler drum band berjumlah 23 siswa. Nilai-nilai karakter yang diteliti diantaranya, sikap disiplin, kerja keras, mandiri, demokratis, bersahabat/komunikatif, cinta damai, peduli sosial, peduli lingkungan dan tanggung jawab. Berdasarkan hasil wawancara dan observasi yang dilakukan menunjukkan bahwa sikap siswa sudah sesuai dengan nilai-nilai karakter. Saran yang dapat disampaikan peneliti untuk sekolah telah menjalankan nilai-nilai karakter dalam pembelajaran ekstrakurikuler drum band SD Al Huda Semarang, hendaknya keadaan seperti ini dipertahankan bahkan ditingkatkan.
\end{abstract}

Kata kunci : nilai karakter, pembelajaran ekstrakurikuler drum band

\begin{abstract}
This type of the research is qualitative descriptive. This study uses data collection methods in the form observation, interviews, and documentation. The results of data analysis that the implementation of drum band extracurricular activities on held every Saturday. The students who participated in the extracurricular drum band 23 students. The character values studied include discipline, hard work, independence, democratic, friendly/communicative, peace-loving, social care, environmental care, and responsibility. Based on the results of interview and observations made indicate that student attitudes are in accordance with character values. The suggestion that researchers can convey to the school that studied is that they have carried out the character values in the extracurricular learning of the drum band in Elementary School Al Huda Semarang, the conditions should be maintained and even improved.
\end{abstract}

Key words: character values, extracurricular learning drum band 


\section{Pendahuluan}

Setiap manusia pasti memiliki sesuatu yang membedakan antara manusia yang satu dengan yang lain. Sesuatu yang membedakan antara manusia yang satu dengan yang lain yaitu sifat atau watak. Karakter yang dimiliki oleh seseorang akan menentukan apakah orang tersebut akan menjadi manusia yang baik atau buruk. Untuk itu, pendidikan karakter sangat diperlukan oleh seorang siswa, karena jika sejak dini anak diajarkan nilai-nilai yang benar akan membentuk perilaku anak kearah yang baik. Megawangi dalam buku Dharma, dkk (2013: 5) menyatakan bahwa pendidikan karakter merupakan sebuah usaha untuk mendidik anak-anak agar dapat mengambil keputusan bijak dan mempraktikkanya dalam kehidupan sehari-hari, sehingga mereka dapat memberikan kontribusi yang positif kepada lingkungannya.

Pendidikan karakter memiliki tujuan untuk mengenalkan dan menanamkan nilai-nilai karakter yang baik pada anak. Menurut Kemdiknas (2010) dalam Wibowo (2013: 15-17) terdapat delapan belas nilai karakter yang harus ditanamkan pada diri anak sedini mungkin, yaitu nilai religius, jujur, toleransi, disiplin, kerja keras, kreatif, mandiri, demokratis, rasa ingin tahu, semangat kebangsaan, cinta tanah air, menghargai prestasi, bersahabat/komunikatif, cinta damai, gemar membaca, peduli lingkungan, peduli sosial, dan tanggung jawab.

Penanaman nilai karakter yang disebutkan diatas dapat diwujudkan melalui kegiatan pembelajaran ekstrakurikuler. Menurut Asmani (2013: 62) kegiatan ekstrakurikuler adalah kegiatan pendidikan di luar mata pelajaran dan pelayanan konseling untuk membantu pengembangkan peserta didik sesuai dengan kebutuhan, potensi, bakat, dan minat mereka melalui kegiatan yang secara khusus diselenggarakan oleh pendidik dan atau tenaga kependidikan yang berkemampuan dan berwenang di sekolah. Menurut Hastuti (2008) program ekstrakurikuler diperuntukkan bagi siswa yang ingin mengembangkanbakat dan kegemarannya. Tujuan dari adanya kegiatan ekstrakurikuler adalah agar siswa memiliki kreatifitas dan pengetahuan tambahan yang sifatnya non akademik. Melalui kegiatan ekstrakurikuler dapat menemukan dan mengembangkan potensi yang dimiliki oleh peserta didik, serta dapat memberikan manfaat sosial yang besar dalam mengembangkan kemampuan berkomunikasi dan bekerja sama dengan orang lain (Suryawan, 2019). Program ekstrakurikuler yang direncanakan di setiap satuan pendidikan mempunyai tujuan utama untuk mendukung kegiatan intrakurikuler (Widayanti, 2018).

Salah satu contoh kegiatan ekstrakurikuler yang dapat mengembangkan potensi, bakat, dan minat siswa adalah ekstrakurikuler drum band. Kegiatan ekstrakurikuler drum band termasuk dalam kategori ekstrakurikuler pilihan dengan bentuk kegiatan olah bakat dan olah minat (sanjaya, 2019). Ekstrakurikuler ini menjadi sarana untuk mengembangkan potensi peserta didik dalam bidang seni musik drum band.

Melalui kegiatan pembelajaran ekstrakurikuler drum band dapat membentuk nilai-nilai karakter yang baik bagi siswa diantaranya sikap disiplin, kerja keras, kreatif, mandiri, bersahabat/komunikatif, dan tanggung jawab. Ekstrakurikuler drum band dapat digunakan oleh siswa untuk mengembangkan bakatnya di bidang musik. Peneliti mengambil ekstrakurikuler drum band dan akan melaksanakan penelitian di SD Al Huda Semarang karena kegiatan ekstrakurikuler tersebut sangat menarik untuk dijadikan sebagai penelitian.

Berdasarkan hasil wawancara dengan ibu Ira Budi Yuliasih, S.Pd. yang dilaksanakan pada hari Kamis, 4 Oktober 2018 di SD Al Huda Semarang, beliau mengatakan bahwa "di SD Al Huda terdapat beberapa ekstrakurikuler yang diadakan di sekolah, salah satunya kegiatan ekstrakurikuler drum band". Ekstrakurikuler ini cukup banyak diminati oleh siswa. Siswa yang mengikuti kegiatan esktrakurikuler drum band berjumlah 23 orang siswa yang terdiri dari laki-laki dan perempuan. Kegiatan dimulai pukul 10.00-11.30 WIB di depan halaman sekolah SD AI Huda. Untuk kaitannya dengan nilai-nilai karakter yang berkaitan dengan sikap disiplin, kerja keras, kreatif, mandiri, bersahabat/komunikatif, dan tanggung jawab, beliau mengatakan "semua sikap tersebut dapat terlihat saat proses pembelajaran ekstrakurikuler berlangsung". 
Berdasarkan latar belakang yang telah disampaikan diatas, peneliti tertarik dan menganggap perlu adanya penelitian tentang "Analisis Nilai-Nilai Karakter Dalam Pembelajaran Ekstrakurikuler Drum Band Di SD Al Huda Semarang".

\section{Metode}

Penelitian ini menggunakan metode penelitian kualitatif. Penelitian ini dilaksanakan di SD AI Huda Semarang. Subjek penelitian ini adalah semua siswa yang mengikuti kegiatan ekstrakurikuler drum band di SD AI Huda Semarang yang berjumlah 23 orang siswa. Data, sumber data dan instrumen dalam penelitian adalah data penelitian, sumber data, instrument penelitian. Prosedur pengumpulan data dalam penilitian ini adalah metode dokumentasi, metode observasi, dan metode wawancara. Keabsahan data dalam penelitian menggunakan perpanjangan pengamatan dan triangulasi. Metode analisis data dalam penelitian ini menggunakan empat tahapan yaitu tahap pengumpulan data, tahap reduksi data, tahap display data, dan tahap penarikan kesimpulan dan/atau tahap verifikasi. Tahapan penelitian yang akan dilakukan dalam penelitian ini meliputi tiga tahap, yaitu tahap persiapan, tahap pelaksanaan, dan tahap analisis data.

\section{Hasil dan Pembahasan}

\section{Pelaksanaan Pembelajaran Ekstrakurikuler Drum Band}

Berdasarkan hasil wawancara dengan Bapak Imam Sumeto selaku guru pelatih ekstrakurikuler drum band akan dibahas mengenai pembelajaran ekstrakurikuler drum band. Kegiatan pembelajaran dilaksanakan setiap hari Sabtu. Latihan dimulai pukul 10.00 WIBdan selesai pada pukul 11.30 WIB. Banyak siswa yang mengikuti ekstrakurikuler drum band. Siswa yang mengikuti ekstrakurikuler drum band seluruhnya berjumlah 23 siswa. Untuk lakilaki berjumlah 12 siswa dan perempuan berjumlah 11 siswa. Menurut narasumber setiap pertemuan mengalami penurunan.

Ketika latihan biasanya siswa tidak menggunakan seragam drum band. Seragam drum band hanya digunakan saat ada acara even di luar sekolah. Namun tidak terdapat foto bersama saat siswa menggunakan seragam drum band ketika ada even di luar. Ketika akan ada pementasan drum band mereka menggunakan kostum untuk membedakan dengan SD lain. Untuk kostum drum band ada dua jenis warna, yaitu biru putih dan merah putih. Jenis musik yang digunakan saat latihan drum band adalah musik dangdut. Adapun jumlah alat musik drum band yang digunakan selama latihan antara lain:

Table 1. Jumlah Alat Musik Drum Band yang digunakan selama latihan

\begin{tabular}{llll}
\hline & No & \multicolumn{1}{c}{ Nama Alat Musik } & Jumlah \\
\hline 1. & Bass Drum & 4 & \\
2. & Snar Drum & 2 & \\
3. & Marching Bells/Bellyra & 2 & \\
4. & Trio Tom-tom & 3 & \\
5. & Bendera & 2 & \\
6. & Stik Mayoret & 20 & 2 \\
\hline
\end{tabular}

Tempat yang digunakan untuk menyimpan alat-alat drum band dibarengkan dengan ruang UKS. Ruang tersebut juga terdapat ruang UKS untuk perempuan dan laki-laki. Jadi walaupun satu ruangan namun terdapat sekat tembok dua pintu untuk pemisah antara ruang UKS laki-laki dan ruang UKS untuk perempuan. Selama kegiatan latihan siswa selalu mengikuti dengan baik. Mereka selalu siap sedia ditempat latihan sebelum guru datang ke tempat latihan. Siswa selalu mengambil alat musiknya sebelum guru datang. Kemudian siswa juga selalu mengembalikan alat musik selesai menggunakan untuk latihan ke tempat semula. Untuk tempat latihan dilakukan di halaman depan kelas. 
Dari yang peneliti amati selama latihan, siswa sangat bersemangat saat mengikuti latihan drum band. Mereka memperhatikan setiap kunci atau lagu yang diajarkan oleh guru pelatih. Saat latihan berlangsung tidak ada siswa yang sibuk bermain sendiri. Mereka semua fokus dengan alat musik yang mereka pegang dan memperhatikan betul setiap perpindahan kunci lagu yang sedang dipelajari.

Selama kegiatan ekstrakurikuler drum band siswa tidak dipungut biaya sedikitpun. Siswa dibebaskan dari biaya apapun. Jadi siswa dengan sepuas hati mengikuti ekstrakurikuler drum band. Dengan ekstrakurikuler drum band ini bisa melatih ketrampilan anak dalam bermain musik. Siswa yang ekstrakurikuler drum band ini juga kebanyakan karena mereka menyukai musik drum band. Tidak terdapat kurikulum yang mengatur dalam ekstrakurikuler drum band tersebut. Ekstrakurikuler drum band hanya berjalan sebagaimana mestinya sesuai dengan instruksi dari pelatih drum band.

Untuk sistem pengawasan dalam ekstrakurikuler drum band tersebut kepala sekolah mengawasinya melalui CCTV. Terkadang kepala sekolah juga mengeceknya secara langsung namun tidak dilihat pada setiap pertemuan. Kepala sekolah mempercayakan semua kepada guru pelatih. Penilaian dicantumkan didalam raport dalam satu semester. Nanti akan terlihat nilai-nilai siswa yang mengikuti ekstrakurikuler drum band.

2. Nilai-nilai Karakter dalam Pembelajaran Ekstrakurikuler Drum Band di SD AI Huda Terdapat sembilan nilai-nilai karakter yang ingin diketahui oleh peneliti. Adapun hasil yang diperoleh peneliti berdasarkan hasil wawancara dengan beberapa sumber di SD AI Huda, antara lain:

1) Disiplin

Untuk sikap disiplin ini, bisa dilihat selama proses latihan berlangsung. Jadi siswa-siswa yang mengikuti esktrakurikuler drum tersebut sudah datang lebih awal sebelum guru pelatih datang. Mereka sudah duduk siap di tempat latihan sebelum guru pelatih datang. Selain itu, mereka juga sudah mengambil alat-alat musik yang akan mereka gunakan saat latihan di gudang tempat menaruh alat musik.

2) Kerja Keras

Untuk sikap kerja keras ini terlihat selama latihan berlangsung. Terlihat semangat anak saat mengikuti ekstrakurikuler drum band dengan gembira. Mereka sangat bekerja keras saat latihan. Apabila ada yang tidak mereka pahami maka mereka akan segera menanyakanya kepada guru pelatih.

3) Mandiri

Sikap mandiri ini terdapat dalam kehidupan sehari-hari mereka saat berada di rumah. Siswa sudah mulai melakukan segala aktivitasnya sendiri tanpa bergantung dengan orang lain. Mereka juga secara mandiri menyiapkan alat musik yang akan digunakan latihan tanpa harus diambilkan atau ditemani oleh guru.

4) Demokratis

Sikap ini terlihat saat anak bisa diarahkan atau menerima arahan dari orang lain. Orang lain disini adalah guru pelatih ekstrakurikuler drum band. Jadi selama kegiatan berlangsung jika ada siswa yang melakukan kesalahan atau ada musik yang kurang pas kemudian guru pelatih memberi masukan kepada siswa, mereka akan mendengarkan arahan yang benar dari guru pelatih. Sehingga latihan dapat berjalan dengan baik karena siswa mau menerima arahan yang diberikan oleh guru pelatih.

5) Bersahabat/komunikatif

Sikap bersahabat ini sudah sangat terlihat dalam ekstrakurikuler ini. Jadi disini terlihat dimana anggota pemain drum band dapat berteman dengan baik satu sama lain. Selain itu, terlihat kerja sama yang terjalin antar anggota pemain. Kerja sama sangat diperlukan dalam kelompok drum band tersebut. Jika tidak ada kerja sama yang terjalin ekstrakurikuler drum band ini tidak dapat berjalan dengan maksimal.

6) Cinta Damai

Dalam hal ini, sikap siswa juga sudah dapat dikatakan cinta damai karena selama latihan berlangsung tidak ada yang saling memukul satu sama lain. Mereka juga selalu 
mengucapkan salam jika bertemu dengan guru dan temannya. Mereka hanya fokus dengan alat musik yang mereka pegang masing-masing.

7) Peduli Sosial

Sikap peduli sosial tersebut juga sudah terbentuk pada diri siswa karena pernah ada kejadian ada siswa yang ingin membagi bekal atau jajan yang dia punyai kepada temannya yang tidak mempunyai bekal atau jajan sama sekali. Secara tidak langsung mereka belajar untuk saling berbagi dengan sesama. Mereka suka membantu jika ada teman yang sedang dalam kesusahan. Bila mendapat bantuan dari orang lain mereka juga mengucapkan terima kasih.

8) Peduli Lingkungan

Sikap ini sudah terbentuk dalam diri siswa sejak awal karena siswa diajarkan untuk membuang sampah ditempatnya. Jadi ketika mereka selesai makan maka bungkusnya mereka buang di tempat sampah. Setiap satu minggu sekali mereka juga diminta kerja bakti di sekolah.

9) Tanggung Jawab

Sikap tanggung jawab ini terlihat saat anak bertanggung jawab dengan alat musik yang mereka pegang. Saat selesai menggunakan alat musiknya mereka mengembalikan alat tersebut ke tempatnya seperti semula. Mereka juga bertanggung jawab dalam menyelesaikan tugas atau PR yang diberikan oleh guru. Sehingga tidak ada siswa yang mengerjakan PR di sekolah karena mereka sudah mengerjakannya di rumah.

Berdasarkan hasil observasi dan wawancara dengan beberapa narasumber seperti kepala sekolah, guru pelatih ekstrakurikuler drum band, guru kelas 2, 3, dan 4, 7 siswa yang mengikuti ekstrakurikuler drum band, dan 2 orang tua wali diperoleh hasil bahwa terdapat nilai-nilai karakter dalam pembelajaran ekstrakurikuler drum band di Al Huda Semarang.

\section{Simpulan dan Saran}

Berdasarkan hasil penelitian dan pembahasan pada penelitian yang telah dilakukan maka dapat diambil simpulan bahwa kegiatan ekstrakurikuler drum band dilaksanakan setiap hari Sabtu pada pukul 10.00 WIB-11.30 WIB. Siswa yang mengikuti ekstrakurikuler drum band berjumlah 23 siswa. Menurut guru pelatih ekstrakurikuler drum band sikap siswa sudah baik selama mengikuti latihan.

Berdasarkan hasil wawancara dengan beberapa narasumber bahwa nilai-nilai karakater seperti disiplin, kerja keras, mandiri, demokratis, bersahabat/komunikatif, cinta damai, peduli sosial, peduli lingkungan, dan tanggung jawab sudah tercermin atau terlihat saat siswa mengikuti latihan drum band. Sikap tersebut terlihat baik selama siswa di sekolah maupun saat siswa berada di rumah. Bentuk penilaian yang dilakukan guru pelatih ekstrakurikuler drum band dilakukan dua kali dalam satu semester. Namun hasil nilai hanya dapat dilihat saat pengambilan raport karena nilai ekstrakurikuler drum band dicantumkan dalam raport.

Adapun saran dalam penelitian ini antara lain Sekolah telah menjalankan nilai-nilai karakter dalam pembelajaran ekstrakurikuler drum band SD AI Huda Semarang, hendaknya keadaan seperti ini dipertahankan bahkan ditingkatkan. Guna menciptakan nilai-nilai karakter yang lebih baik, sekolah perlu mengadakan pembelajaran nilai karakter diluar jam pelajaran. Harapannya agar terbentuk karakter yang baik setiap pada setiap siswa.

\section{Daftar Pustaka}

Adisusilo, Sutarjo. 2013. Pembelajaran Nilai-Karakter Kontruktivisme dan VCT sebagai inovasi Pendeketan Pembelajaran Afektif. Jakarta: Rajawali Pers.

Arikunto, Suharsimi. 2014. Prosedur Penelitian Suatu Pendeketan Praktik. Jakarta: Rineka Cipta.

Arifin, Y., Setyosari, P. and Ulfa, S., 2018. Pengembangan Multimedia Interaktif Materi Sandi Morse Dalam Kegiatan Ekstrakurikuler Kepramukaan Bagi Siswa Kelas V. Jurnal Kajian Teknologi Pendidikan, Volume 1, Nomor 2, pp.115-122. 
Asmani, Jamal Ma'mur. 2013. Buku Panduan Internalisasi Pendidikan Karakter di Sekolah. Jogjakarta: DIVA Press.

Bungin, M. Burhan. 2015. Penelitian Kualitatif: Komunikasi, Ekonomi, Kebijakan Publik, dan IImu Sosial Lainnya. Jakarta: Prenada Media Group.

Creswell W. John. 2010. Research Design Pendekatan Kuantitatif, Kualitatif, dan Mixed). Yogyakarta: Pustaka Pelajar.

Dharma, dkk. 2013. Pendidikan Karakter Kajian Teori dan Praktik di Sekolah. Bandung: PT Remaja Sodakarya.

Hastuti, T.A., 2008. Kontribusi ekstrakurikuler bolabasket terhadap pembibitan atlet dan peningkatan kesegaran jasmani. Jurnal Pendidikan Jasmani Indonesia, Vol. 5, Nomor 1.

Haryanggita, Achmadhan Katon. 2015. "Pembelajaran Ekstrakurikuler Drum Band di Madrasah Tsanawiyah Negeri Kedunggalar Ngawi". Terdapat pada jurnal Pendidikan Sendratasik Vol. 3.

Herdiansyah, Haris. 2014. Metodologi Penelitian Kualitatif untuk IImu-ilmu Sosial. Jakarta: Salemba Humanika.

Kurniawan, Eka Yulyawan. "Pendidikan Karakter dalam Kegiatan Ekstrakurikuler Drumband di Sekolah dasar NegeriMekarsari II Kabupaten tanggerang". Jurnal Pendidikan dan kajian Seni 3.2 (2018).

Mangesthi, Veronika Priella. 2016. "Analisis Nilai-nilai Karakter pada Film Kartun Curious George". Skripsi Universitas PGRI Semarang.

Moleong, Lexy J. 2011. Metodologi Penelitian Kualitatif. Bandung: PT Remaja Rosdakarya.

Putra, N.E. and Eminita, V., 2018, July. PENGARUH EKSTRAKURIKULER TERHADAP KEAKTIFAN DAN HASIL BELAJAR MATEMATIKA SISWA. In Prosiding Seminar Nasional Pendidikan. Vol. 1, No. 1.

Sanjaya, Y., Habsary, D. and Kurniawan, A., 2019. Evaluasi Pembelajaran Tari Muli Siger Menggunakan Anates pada Ekstrakurikuler di SMA AI Huda Lampung Selatan. Jurnal Seni dan Pembelajaran, Volume 7, Nomor 7.

Sukmadinata, Nana Syaodih. 2016. Metode Penelitian Pendidikan. Bandung: PT Remaja Rosdakarya.

Sukmawati, D., 2015. Penerapan Pembelajaran Renang Gaya Bebas Terhadap Hasil Belajar Renang Gaya Bebas (Studi Pada Siswa Ekstrakurikuler Smp Santa Maria Surabaya). Jurnal Pendidikan Olahraga dan Kesehatan, Volume 3, Nomor 2.

Sugiyono. 2015. Metode Penelitian Pendidikan (Pendekatan Kuantitatif, Kualitatif, dan R\&D). Bandung: Alfabeta

Suryawan, I.G., 2019. PEMBELAJARAN EKSTRAKULIKULER SENI LUKIS KACA DI SMP NEGERI 3 SUKASADA. Brikolase: Jurnal Kajian Teori, Praktik dan Wacana Seni Budaya Rupa, Volume 10, Nomor 2, pp.146-157.

Susanto, Ahmad. 2016. Teori Belajar \& Pembelajaran di Sekolah. Jakarta: Prenadamedia Group.

Widayati, D.W., 2018. MANAJEMEN EKSTRAKURIKULER KARAWITAN DAN KAITANNYA DENGAN PENANAMAN NILAI-NILAI LUHUR BUDAYA BANGSA. SOSIOHUMANIORA: Jurnal IImiah IImu Sosial dan Humaniora, Volume 4, Nomor 2.

Yaumi, Muhammad. 2014.Pendidikan Karakter: Landasan, Pilar, danImplementasi. Jakarta: Prenadamedia Group. 